\title{
Fatty Acid and Polar Lipid Composition of the Genus Amycolatopsis: Application of Fast Atom Bombardment-Mass Spectrometry to Structure Analysis of Underivatized Phospholipids
}

\author{
A. F. YASSIN,${ }^{1 *}$ B. HAGGENEI, ${ }^{2}$ H. BUDZIKIEWICZ, ${ }^{2}$ AND K. P. SCHAAL ${ }^{1}$ \\ Institut für Medizinische Mikrobiologie und Immunologie der Universität Bonn, Sigmund-Freud-Strasse 25, \\ D-5300 Bonn 1, ${ }^{1}$ and Institut für Organische Chemie der Universität zu Köln, D-5000 Köln 41, ${ }^{2}$ Germany
}

\begin{abstract}
Phospholipid patterns of 15 representative strains of the genus Amycolatopsis were recorded by twodimensional thin-layer chromatography. The structure analysis of the isolated phospholipids was verified by fast atom bombardment-mass spectroscopy. The positive- and negative-ion spectra of the partially purified phospholipid fractions qualitatively reflect their distinctive composition. All strains contained diphosphatidylglycerol, phosphatidylglycerol, and phosphatidylinositol. Two different types of phosphatidylethanolamine and phosphatidylmethylethanolamine were detected, viz., compounds with or without hydroxy fatty acids. These phospholipid patterns underline the integrity of the genus. Fast atom bombardment-mass spectrometry analysis of phospholipid patterns may serve as an aid for differentiation of bacterial species.
\end{abstract}

Valuable taxonomic information for actinomycete systematics has been derived from two-dimensional thin-layer chromatographic (TLC) analyses of polar lipids (16, 25-27). Phospholipids are the most common actinomycete polar lipids, and they have been proven to be of value as taxonomic markers $(10,15,16,18,21,22,24,32)$. The phospholipids most frequently encountered in actinomycete wall envelopes include phosphatidylcholine (PC), phosphatidyl-

TABLE 1. Descriptions and sources of Amycolatopsis strains

\begin{tabular}{|c|c|}
\hline Designation $^{a}$ & History \\
\hline A. azurea DSM $43854^{\mathrm{T}} \ldots .$. & $\begin{array}{l}\text { A. Hensen, Fachbereich Biologie der Philips-Universität Marburg/Lahn, Germany (Pseudono- } \\
\text { cardia azurea); NRRL 11412; S. Omura, AM 3696, soil, Japan; produces azureomycins A } \\
\text { and B }\end{array}$ \\
\hline
\end{tabular}

A. mediterranei ATCC $13685^{\mathrm{T}}$ DSM $40501^{\mathrm{T}}$ .Lepetit Laboratories, ME83/973 (Streptomyces mediterranei), soil; produces rifamycin .Lepetit Laboratories, ME83/973

A. methanolica NCIB $11946^{\mathrm{T}}$ J. G. Kuenen, Laboratory of Microbiology, Technical University of Delft, Delft, The Netherlands, LMD 80.32 (Nocardia sp.), soil, New Guinea

A. orientalis subsp. orientalis ATCC $19795^{\mathrm{T}}$

DSM $43387^{\mathrm{T}}$

DSM 43388

N875

N876

N878

N879

A. orientalis subsp. lurida DSM $43134^{\mathrm{T}}$...

A. rugosa ATCC $43014^{\mathrm{T}}$

...M. P. Lechevalier, Rutgers University, Piscataway, N.J., IMRU 3760; R. E. Gordon; C. di Marco; cow rumen

E. V. Shirling, Ohio Wesleyan University, Delaware, Ohio, ISP 5040 (Streptomyces orientalis); P. Pittinger, M43-05865, soil, Asia; produces vancomycin E. B. Shirling, ISP 5040

M. Goodfellow, N858; R. E. Gordon, IMRU 1390; J. Scharfen, W-113/66

R. E. Gordon, Rutgers University, Piscataway, N.J., IMRU 1311 (Nocardia-Streptomyces group); M. P. Lechevalier, FT 19; clinical specimen

.R. E. Gordon, IMRU 1409 (Nocardia brasiliensis); J. Scharfen, AK 4348; clinical specimen

R. E. Gordon, IMRU 1592 (Micropolyspora sp.); L. K. Georg, W-2101; soil, Sudan

R. E. Gordon, IMRU 1601 (Micropolyspora sp.); L. K. Georg, W-2156; soil, Sudan

A. sulphurea ATCC $27624^{\mathrm{T}}$

Abbott Laboratories, M-319 (Nocardia sulphurea); garden soil; produces chelocardin

\footnotetext{
* Corresponding author.
} 

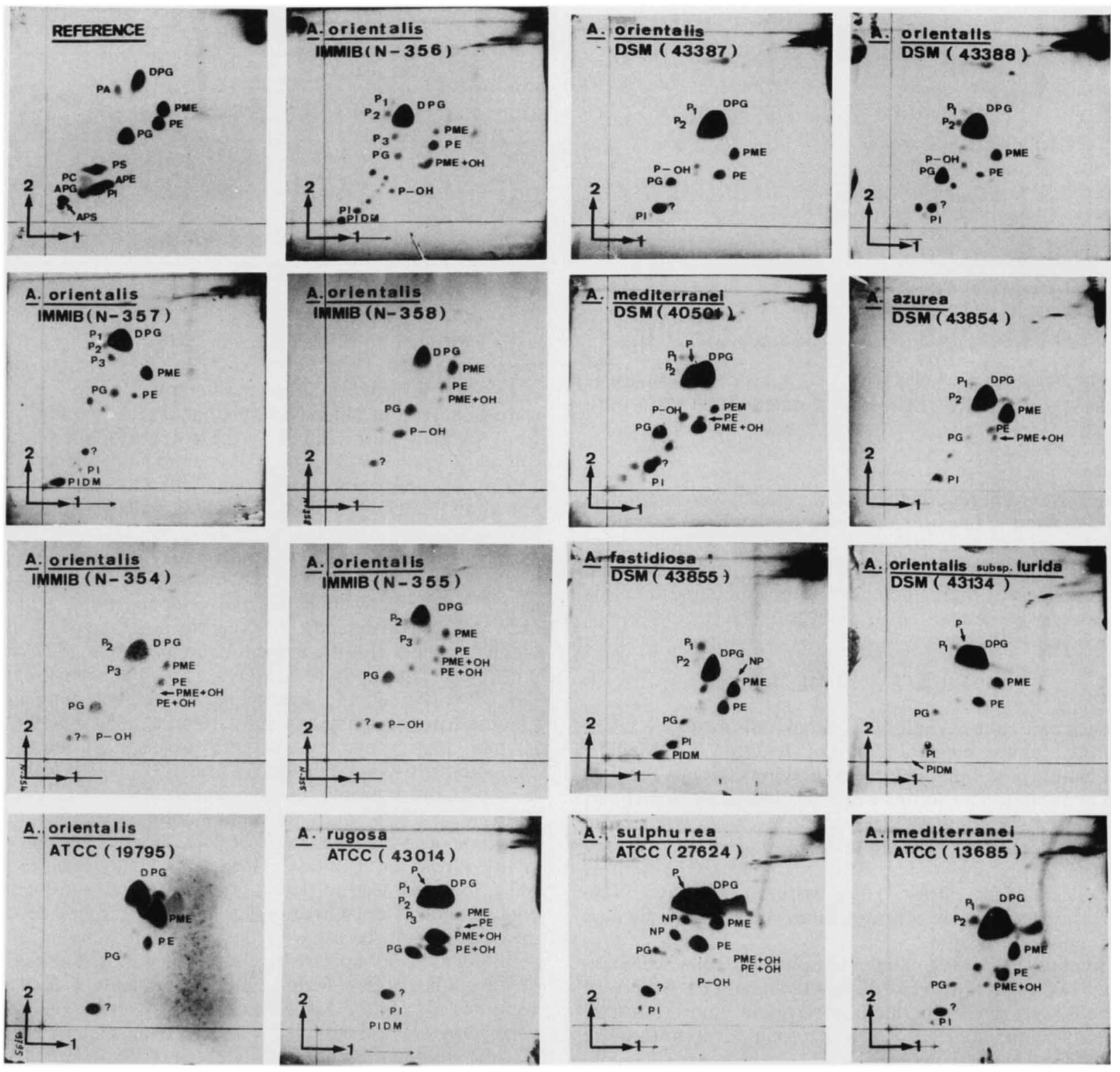

FIG. 1. Two-dimensional TLC of polar lipids from Amycolatopsis strains. Chloroform-methanol-water (65:25:4 [vol/vol]) was used as the solvent in the first direction, and chloroform-acetic acid-methanol-water (80:15:12:4 [vol/vol]) was used in the second direction. PC, phosphatidylcholine; IMMIB, Institute for Medical Microbiology and Immunology of the University of Bonn.

glycerol (PG), phosphatidylethanolamine (PE), and phosphatidylinositol (PI). Less commonly detected polar lipids include phosphatidylmethylethanolamine (PME).

Lechevalier et al. $(16,18)$ divided the phospholipids extracted from aerobic actinomycetes into five groups on the basis of the distribution of certain nitrogenous phospholipids. Members of the family Pseudonocardiaceae were recovered in two of these groups. Among them, Amycolatopsis, Kibdelosporangium, and Saccharomonospora strains have a type II phospholipid pattern; that means that they contain PE but not phosphatidylcholine.

Characterization and identification of microorganisms constitute a major goal of diagnostic microbiology. Many systems and methods have been developed for this task, but in recent years increasing emphasis has been placed on the need to reduce the time involved and to introduce automated systems into diagnostic microbiology. One of the methods likely to enable rapid characterization of microorganisms is fast atom bombardment (FAB)-mass spectrometry (MS). As shown by Barber et al. (4), polar, nonvolatile compounds can be analyzed. Fenwick et al. (8) showed that FAB provides abundant quasimolecular ions for phospholipids, as well as characteristic fragment ions. A comparative study of various soft ionization techniques has been reported for the structural characterization of phospholipids $(2,9,19,35)$. Münster and Budzikiewicz (28) and Münster et al. (29) showed that negative-ion FAB-MS is a suitable method for analysis of intact phospholipids. Heller et al. $(11,12)$ and Pramanik et al. (31) reported the use of negative-ion FAB and tandem MS in profiling mixtures of bacterial phospholipids.

In this study, partially purified classes of phospholipids 


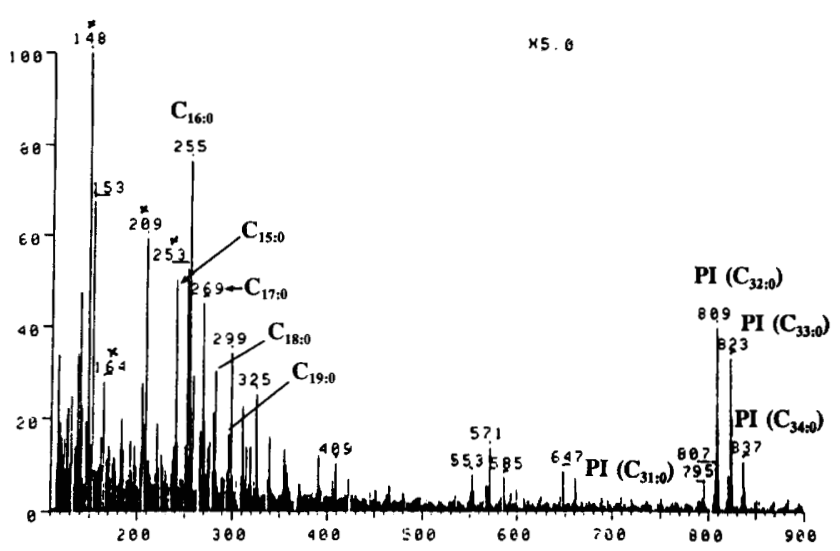

FIG. 2. Negative-ion FAB mass spectrum of the components separated by preparative TLC from $A$. fastidiosa DSM $43855^{\mathrm{T}}$ (PI).

isolated from different species of the genus Amycolatopsis were subjected to negative- and positive-ion FAB as well as FAB-tandem MS to verify their structural assignments as already identified by two-dimensional TLC and to evaluate the usefulness of these methods for phospholipid analysis from bacterial sources.

\section{MATERLALS AND METHODS}

Strains and culture conditions. Stock cultures were taken from the culture collection of the Institute for Medical Microbiology and Immunology of the University of Bonn as listed in Table 1. The strains were maintained on brain heart infusion agar (Difco) at $4^{\circ} \mathrm{C}$. The strains were grown in brain heart infusion broth (Difco) under agitation on a rotary shaker $(150 \mathrm{rpm})$ for 7 days. At maximum growth, cultures were checked for purity, killed with formaldehyde (1\% [vol/vol]), harvested by centrifugation, washed with distilled water, and freeze-dried.

Extraction of phospholipids. Lyophilized cells were extracted overnight with chloroform-methanol (2:1 [vol/vol]). The cells were then separated by filtration, and the filtrate was evaporated under vacuum with a rotary evaporator. The precipitation method of Andrews (1), which uses ice-cold acetone, was used to separate the phospholipids from other lipids. The dry residue was dissolved in 2.5 to $5 \mu \mathrm{l}$ of chloroform per $\mathrm{mg}$ and cooled in a deep freeze for $10 \mathrm{~min}$. Excess ice-cold acetone was added until no more milky precipitate formed. The mixture was centrifuged at $2,000 \times$ $g$ for $10 \mathrm{~min}$ at $0^{\circ} \mathrm{C}$ to pellet the precipitate, and the supernatant was transferred to another stoppered tube. The precipitate was further washed with $1 \mathrm{ml}$ of ice-cold acetone per mg. Both tubes were left in a freezer overnight, and the precipitates were collected on the following day and dried thoroughly under nitrogen.

Purification of phospholipids. The dry precipitate was dissolved in $5 \mathrm{ml}$ of chloroform-methanol-water $(60: 30: 4.5$ [vol/vol]) and passed through a column $(0.9 \mathrm{by} 15 \mathrm{~cm})$ of Sephadex G25 (coarse) at a rate of $6 \mathrm{drops} / \mathrm{min}$ with the same solvent as the eluent. The effluent was taken to dryness under a stream of nitrogen. The residue was redissolved in 5 $\mathrm{ml}$ of chloroform and mixed by vibration for $1 \mathrm{~min}$ with $3 \mathrm{ml}$ of $0.5 \% \mathrm{NaCl}$. The emulsion was broken by centrifugation, the milky supernatant was discarded, and the washing process was repeated with fresh saline. The lower chloroform
TABLE 2. Quasimolecular ion and fatty acid composition of PI isolated from $A$. fastidiosa DSM $43855^{\mathrm{T}}$

\begin{tabular}{ccccc}
\hline \multicolumn{3}{c}{ Peak $(m / z)$ of: } & & Fatty acids \\
\cline { 1 - 3 }$[\mathrm{M}-\mathrm{H}]^{-}$ & {$[\mathrm{M}+\mathrm{H}]^{+}$} & {$[\mathrm{M}+\mathrm{Na}]^{+}$} & $\begin{array}{c}{[\mathrm{M}+2} \\
\mathrm{Na}-\mathrm{H}]^{+}\end{array}$ & \\
\hline 795 & 797 & 819 & 841 & {$\left[\mathrm{C}_{15: 0} / \mathrm{C}_{16: 0}\right]$} \\
809 & 811 & 833 & 855 & {$\left[\mathrm{C}_{16: 0} / \mathrm{C}_{16: 0}\right],\left[\mathrm{C}_{15: 0} / \mathrm{C}_{17: 0}\right]$} \\
823 & 825 & 847 & 869 & {$\left[\mathrm{C}_{17: 0} / \mathrm{C}_{16: 0}\right],\left[\mathrm{C}_{15: 0} / \mathrm{C}_{18: 0}\right]$} \\
837 & 839 & 861 & 833 & {$\left[\mathrm{C}_{17: 0} / \mathrm{C}_{17: 0}\right],\left[\mathrm{C}_{16: 0} / \mathrm{C}_{18: 0}\right]$,} \\
& & & & {$\left[\mathrm{C}_{15: 0} / \mathrm{C}_{19: 0}\right]$} \\
\hline
\end{tabular}

layer was taken to dryness under a stream of nitrogen and used for TLC.

Two-dimensional TLC. The purified phospholipid extracts were dissolved in chloroform-methanol (2:1 [vol/vol]), and $10-\mu l$ samples were applied to the corners of six silica gel (Merck Kieselgel $60 \mathrm{~F}_{254}$ no. 5554) aluminium sheets (10 by $10 \mathrm{~cm})$. Chromatography was done with chloroform-methanol-water (65:25:4 [vol/vol]) in the first direction and chloroform-acetic acid-methanol-water (40:7.5:6:2 [vol/vol]) in the second direction (25). To determine the type of lipids present on the chromatograms, the following differential stains were used. Five percent ethanolic molybdophosphoric acid was used as a general detector to reveal the presence of all lipids. Upon spraying with the reagent and charring at $180^{\circ} \mathrm{C}$ for 5 min, blue spots appeared. Merck ninhydrin spray reagent (no. 6758) was used to detect compounds containing amino groups. After spraying and subsequent heating at $110^{\circ} \mathrm{C}$ for $10 \mathrm{~min}$, pink spots revealed the presence of the amino compounds. $\alpha$-Naphtholsulfuric acid (13) reagent was used to detect the presence of glycolipids. After spraying and charring at $120^{\circ} \mathrm{C}$ until maximum color developed, bluepurple spots were obtained. Periodate-Schiff reagent was adapted from the method devised by Baddiley et al. (3) and Shaw (32) and used to detect glycolipids and phosphatides which contain vicinal hydroxyl groups. The method depends on cleavage of glycols with periodate and staining of the resulting aldehydolipids with Schiff reagent. The periodatepositive lipids appear within $1 \mathrm{~min}$ as pink-mauve spots. The identities of PI and PG were verified by this reagent. A dried chromatogram was sprayed with the Draggendorff reagent $(5,34)$, whereupon phosphatidylcholine, PE, and PME appeared immediately as yellow-orange spots on a yellow

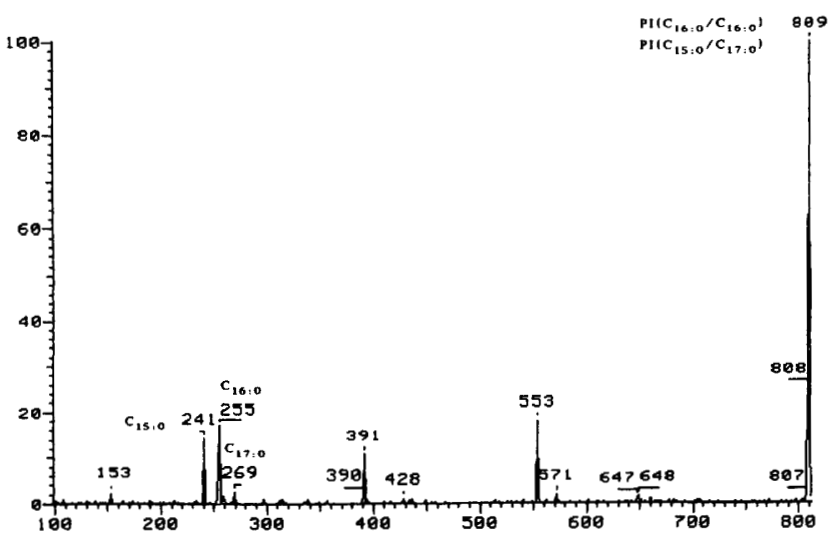

FIG. 3. CA spectrum of $[\mathrm{M}-\mathrm{H}]^{-}(m / z$ 809) from $A$. fastidiosa DSM $43855^{\mathrm{T}}$ (PI). 


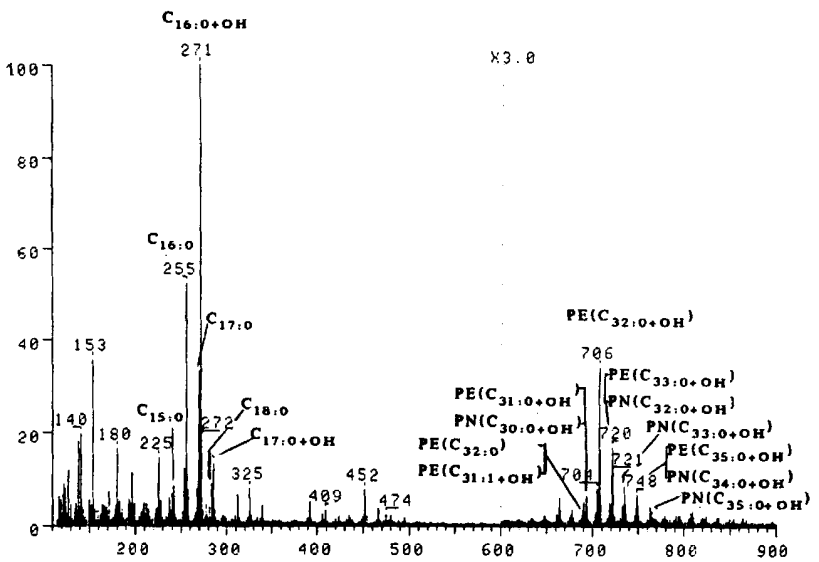

FIG. 4. Negative-ion FAB mass spectrum of the lowest weight ninhydrin-positive components separated by TLC from $A$. rugosa ATCC $43014^{\mathrm{T}}$ (PE plus OH). PN, PME.

background. Dittmer and Lester reagent $(7,33)$ is specific for phospholipids and detects as little as $10 \mu \mathrm{g}$. Phospholipids appear as blue spots on a white background within a few minutes without heating.

Preparative TLC. The phospholipid mixture was fractionated into partially purified components by TLC with silica gel (Merck Kieselgel $F_{254}$ no. 5554) aluminum sheets and a developing solvent of chloroform-methanol-acetic acid-water $(25: 15: 4: 2$ [vol/vol] $)$. The developed plate was exposed to iodine vapor, and the phospholipid bands were marked with a pen and left in a fume hood until the iodine evaporated. The bands were then scraped off into a centrifuge tube, and the phospholipids were eluted from silica gel with chloroform-methanol (2:1 [vol/vol]), separated by centrifugation, and then concentrated by evaporation of the excess chloroform-methanol under a nitrogen stream. They were stored at $-20^{\circ} \mathrm{C}$ until analyzed.

MS. Positive- and negative-ion FAB spectra were recorded with a 731 mass spectrometer (Finnigan MAT, Bremen, Germany) equipped with an 11 NF FAB gun (Ion Tech Ltd., Teddington, United Kingdom). Measurements were made with a xenon gas pressure of $10^{-5}$ torr, the FAB potential was $7 \mathrm{kV}$, and the source temperature was ca. $30^{\circ} \mathrm{C}$. The spectrometer was operated at an accelerating voltage of $8 \mathrm{kV}$, the postacceleration for positive-ion $\mathrm{FAB}$ was $5 \mathrm{kV}$, and that for negative-ion $\mathrm{FAB}$ was $7.5 \mathrm{kV}$. Collision activation (CA) measurements were performed with an HSQ 30 (Finnigan MAT) magneto-electrostatic quadropole-quadropole configuration (BEQQ) instrument. Argon was used as the collision gas, the collision energy was $70 \mathrm{eV}$, and the parent ion intensity was reduced to 70 to $50 \%$. The resolution in the magneto-electrostatic (BE) part was 1,000 , and the resolution in the quadropole-quadropole (QQ)

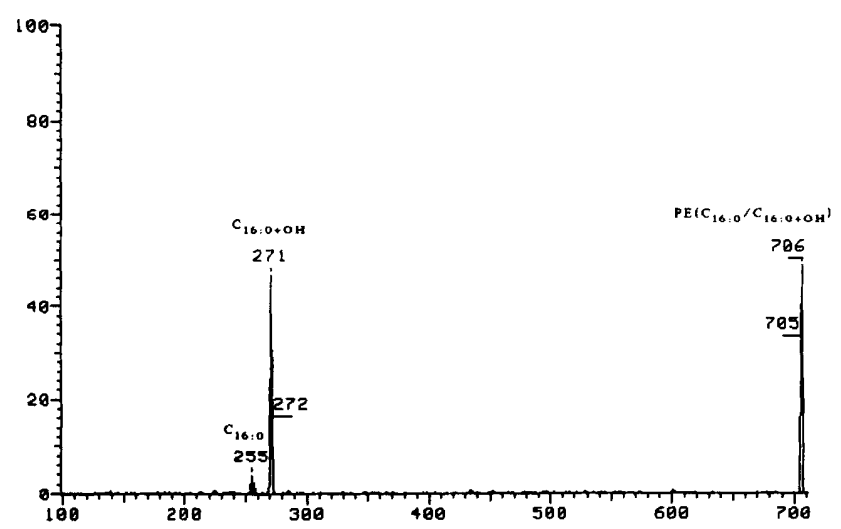

FIG. 5. CA spectrum of $[\mathrm{M}-\mathrm{H}]^{-}(m / z$ 706) from $A$. nugosa ATCC $43014^{\mathrm{T}}$ (PE plus OH).

part was unit mass resolution. Scan time was 100 mass units $/ 5 \mathrm{~s}$, and the results of five consecutive scans were averaged.

Samples were dissolved in a mixture of $\mathrm{CHCl}_{3}-\mathrm{CH}_{3} \mathrm{OH}$ $\mathrm{H}_{2} \mathrm{O}(86: 14: 1$ [vol/vol]) and deposited in a matrix on a copper target. $m$-Nitrobenzyl alcohol was used as a matrix for positive-ion FAB, and $2 \mu \mathrm{l}$ of this substance was mixed with $2 \mu \mathrm{l}$ of solution. Diethanolamine was used as a matrix for negative-ion FAB, and $5 \mu \mathrm{l}$ was mixed with $5 \mu$ l of solution; $2 \mu \mathrm{l}$ of this mixture was applied to the target.

\section{RESULTS}

TLC. The results of two-dimensional TLC analyses of the polar lipids of the organisms studied are shown in Fig. 1. The patterns obtained were quite complex, and some components could not be positively identified. The remaining lipids, however, were clearly recognized by their characteristic chromatographic migration and staining properties with specific spray reagents. The most mobile phospholipid in all cases cochromatographed with authentic diphosphatidylglycerol (DPG) and was invariably present in all strains as a main component. However, the DPG chromatographic spots of Amycolatopsis mediterranei DSM $40501^{\mathrm{T}}, A$. orientalis subsp. lurida DSM $43134^{\mathrm{T}}$ (Fig. 1), $A$. rugosa ATCC $43014^{\mathrm{T}}$, and $A$. sulphurea ATCC $27624^{\mathrm{T}}$ were not homogeneous. They showed overlapping spots with two heads, which may be explained by the presence of another accompanying phospholipid having the same migration behavior and designated $P$. Other spots which react with phosphomolybdic acid and Dittmer reagent were located to the left of the DPG spot and were characterized as phospholipids $P_{2}$ and $P_{3}$. In addition, a third spot, designated $P_{1}$, reacted with both $\alpha$-naphthol and phosphomolybdic acid but did not react with Dittmer reagent, indicating that it was a glycolipid.

TABLE 3. Quasimolecular ion and fatty acid composition of PE-OH isolated from $A$. fastidiosa DSM $43855^{\mathrm{T}}$

\begin{tabular}{|c|c|c|c|c|}
\hline \multicolumn{4}{|c|}{ Peak $(m / z)$ of: } & \multirow{2}{*}{ Fatty acids } \\
\hline$[\mathrm{M}-\mathrm{H}]^{-}$ & {$[\mathbf{M}+\mathbf{H}]^{+}$} & {$[\mathrm{M}+\mathrm{Na}]^{+}$} & {$[\mathrm{M}+2 \mathrm{Na}-\mathrm{H}]^{+}$} & \\
\hline $\begin{array}{l}690 \\
692 \\
706 \\
720 \\
748\end{array}$ & $\begin{array}{l}692 \\
694 \\
708 \\
722 \\
750\end{array}$ & $\begin{array}{l}714 \\
716 \\
730 \\
744 \\
772\end{array}$ & $\begin{array}{l}736 \\
738 \\
752 \\
766 \\
794\end{array}$ & $\begin{array}{l}{\left[\mathrm{C}_{15: 1} / \mathrm{C}_{16: 0}+\mathrm{OH}\right],\left[\mathrm{C}_{16: 0} / \mathrm{C}_{16: 0}\right],\left[\mathrm{C}_{15: 0} / \mathrm{C}_{17: 0}\right]} \\
{\left[\mathrm{C}_{16: 0} / \mathrm{C}_{15: 0}+\mathrm{OH}\right]} \\
{\left[\mathrm{C}_{16: 0} / \mathrm{C}_{16: 0}+\mathrm{OH}\right]} \\
{\left[\mathrm{C}_{16: 0} / \mathrm{C}_{17: 0}+\mathrm{OH}\right]} \\
{\left[\mathrm{C}_{16: 0} / \mathrm{C}_{19: 0}+\mathrm{OH}\right]}\end{array}$ \\
\hline
\end{tabular}


TABLE 4. Quasimolecular ion and fatty acid composition of PME-OH isolated from A. rugosa ATCC $43014^{\mathrm{T}}$

\begin{tabular}{|c|c|c|c|c|}
\hline \multicolumn{4}{|c|}{ Peak $(m / z)$ of: } & \multirow{2}{*}{ Fatty acids } \\
\hline$[\mathrm{M}-\mathrm{H}]^{-}$ & {$[\mathrm{M}+\mathrm{H}]^{+}$} & {$[\mathrm{M}+\mathrm{Na}]^{+}$} & {$[\mathrm{M}+2 \mathrm{Na}-\mathrm{H}]^{+}$} & \\
\hline 692 & 694 & 716 & 738 & {$\left[\mathrm{C}_{14: 0} / \mathrm{C}_{16: 0}+\mathrm{OH}\right]$} \\
\hline 720 & 722 & 744 & 766 & {$\left[\mathrm{C}_{16: 0} / \mathrm{C}_{16: 0}+\mathrm{OH}\right]$} \\
\hline 734 & 736 & 758 & 780 & {$\left[\mathrm{C}_{17: 0} / \mathrm{C}_{16: 0}+\mathrm{OH}\right],\left[\mathrm{C}_{16: 0} / \mathrm{C}_{17: 0}+\mathrm{OH}\right]$} \\
\hline 748 & 750 & 772 & 794 & {$\left[\mathrm{C}_{18 \cdot 0} / \mathrm{C}_{16: 0}+\mathrm{OH}\right]$} \\
\hline 762 & 764 & 786 & 808 & {$\left[\mathrm{C}_{16: 0} / \mathrm{C}_{19: 0}+\mathrm{OH}\right],\left[\mathrm{C}_{19: 0} / \mathrm{C}_{16: 0}+\mathrm{OH}\right],\left[\mathrm{C}_{18: 0} / \mathrm{C}_{17: 0}+\mathrm{OH}\right]$} \\
\hline
\end{tabular}

Four ninhydrin-positive spots were detected on TLC plates of the strains studied: two spots cochromatographed with authentic PME and PE, and two more polar spots corresponded to PME and PE acylated with hydroxy fatty acids. The structures of these four compounds were verified with FAB-MS as described in detail below. Other unidentified ninhydrin-positive phospholipids were also present in $A$. orientalis DSM $43387^{\mathrm{T}}$ and DSM 43388 and $A$. mediterranei DSM $40501^{\mathrm{T}}$ and were designated NP.

PG, PI, and a lipid which had the chromatographic mobility and staining properties of a diacylated PI dimannoside isolated from nocardiae were easily detected by their rapid reaction with periodate-Schiff reagent. The last two compounds were also characterized by their reaction with $\alpha$-naphthol. Other unidentified phospholipids possessing vicinal $\mathrm{OH}$ groups and reacting with the periodate-Schiff reagent were also present in $A$. orientalis ATCC $19795^{\mathrm{T}}, A$. rugosa ATCC $43014^{\mathrm{T}}, A$. sulphurea ATCC $27624^{\mathrm{T}}, A$. mediterranei ATCC $13685^{\mathrm{T}}$, and all of the Institute for Medical Microbiology and Immunology of the University of Bonn strains, $A$. orientalis DSM 43388, $A$. mediterranei DSM $40501^{\mathrm{T}}$, and $A$. orientalis subsp. lurida $\mathrm{DSM} 43134^{\mathrm{T}}$, and designated $\mathrm{P}-\mathrm{OH}$.

FAB-MS and the identities of the different components. To verify the identities of the different components as tentatively identified by both chromatographic behavior and color reactions, partially purified fractions isolated by preparative TLC were subjected to FAB-MS. The positive- and negative-ion FAB spectra show a number of ions in the molecular ion region. In addition to the quasimolecular ion $[\mathrm{M}-\mathrm{H}]^{-}$in the negative-ion FAB spectra and $[\mathrm{M}+\mathrm{H}]^{+}$in the positiveion FAB spectra, there were accompanying ions due to $[\mathrm{M}+$ $\mathrm{Na}]^{+}$and $[\mathrm{M}+2 \mathrm{Na}-\mathrm{H}]^{+}$. The fragmentation pattern of intact phospholipids in both positive- and negative-ion FAB spectra shows three main regions: the molecular ion region

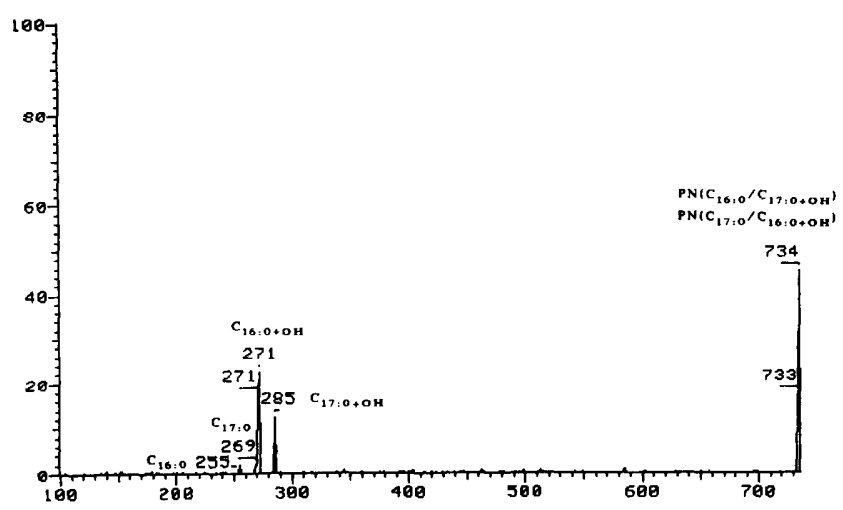

FIG. 6. CA spectrum of $[\mathrm{M}-\mathrm{H}]^{-}(m / z$ 734) from $A$. fastidiosa DSM $43855^{\mathrm{T}}$ (PME plus OH). PN, PME.
( $m / z 650$ to 900$)$, the fatty acid region $(m / z 200$ to 340$)$, and the phosphate ester region $(\mathrm{m} / z 140$ to 260$)$.

Figure 2 shows the positive- and negative-ion FAB spectra of a fraction isolated from $A$. fastidiosa DSM $43855^{\mathrm{T}}$ which was tentatively identified as PI by its color reaction. The quasimolecular ions at $m / z 795,809,823$, and 837 were interpreted as corresponding to a series of PI with fatty acids with increasing chain lengths. The interpretation of these quasimolecular ions is shown in Table 2.

The negative-ion FAB spectrum shows peaks at $m / z 299$, $259,281,241$, and 297 which characterize the inositol phosphate part of the molecule. Further support for the abovedescribed structural assignment was supplied by the FABtandem mass spectrum of the quasimolecular ion at $\mathrm{m} / \mathrm{z} 809$. The daughter ion spectrum generated from $\mathrm{m} / \mathrm{z} 809$ displayed ions at $m / z$ 553, 391, 255, 241, and 269 (Fig. 3).

TLC revealed the presence of four ninhydrin-positive components. FAB-MS analysis of the lowest fractions showed quasimolecular ions at $m / z$ 690, 692, 706, 720, and 748 (Fig. 4). These were interpreted as corresponding mainly to a series of PE that contained hydroxylated fatty acids (Table 3). In the lower-molecular-weight region, intense peaks at $m / z 180$ and 140 characterized the phosphate ethanolamine part of the molecules.

These structural assignments of PE were supported by tandem MS of the daughter ion at $\mathrm{m} / \mathrm{z} 706$ (Fig. 5). The spectrum generated from $\mathrm{m} / \mathrm{z} 706$ displayed a peak with high intensity at $m / z 255$ and less intensive peaks at $m / z 239,241$, 269 , and 271 which characterize the fatty acids. The peak at $\mathrm{m} / \mathrm{z} 271$ corresponds to a hydroxylated fatty acid.

FAB-MS analysis of the lower-middle ninhydrin-positive fractions showed quasimolecular ions at $m / z 692,720,734$, 748, and 762 (Table 4). Negative-ion FAB showed intensive peaks at $\mathrm{m} / \mathrm{z} 194$ and 154 which are characteristic for a phosphate methylethanolamine moiety in the molecule. Therefore, these quasimolecular ions were interpreted as corresponding to PME with different fatty acid combinations (Table 4). The tandem mass spectrum of the quasimolecular ion at $\mathrm{m} / \mathrm{z} 734$ (Fig. 6) supports the above interpretation. Intensive ions at $m / z 269,271$, and 285 correspond to the fatty acid components of the phospholipids.

TABLE 5. Quasimolecular ion and fatty acid composition of PME isolated from $A$. rugosa ATCC $43014^{\mathrm{T}}$

\begin{tabular}{|c|c|c|c|c|}
\hline \multicolumn{4}{|c|}{ Peak $(m / z)$ of: } & \multirow[b]{2}{*}{ Fatty acids } \\
\hline$[\mathrm{M}-\mathrm{H}]^{-}$ & {$[\mathbf{M}+\mathbf{H}]^{+}$} & {$\left[\mathrm{M}+\mathrm{Na}^{+}\right.$} & $\begin{array}{l}{[\mathrm{M}+2} \\
\mathrm{Na}-\mathrm{H}]^{+}\end{array}$ & \\
\hline 704 & 706 & 728 & 750 & {$\left[C_{16: 0} / C_{16: 0}\right]$} \\
\hline 718 & 720 & 742 & 764 & {$\left[C_{16: 0} / C_{17: 0}\right],\left[C_{15: 0} / C_{18: 0}\right]$} \\
\hline 732 & 734 & 756 & 778 & {$\left[\mathrm{C}_{17: 0} / \mathrm{C}_{17: 0}\right],\left[\mathrm{C}_{16: 0} / \mathrm{C}_{18: 0}\right]$,} \\
\hline 746 & 748 & 770 & 792 & {$\left[\mathrm{C}_{18: 0} / \mathrm{C}_{16: 0}\right]$} \\
\hline
\end{tabular}


TABLE 6. Quasimolecular ion and fatty acid composition of PE isolated from $A$. fastidiosa DSM $43855^{\mathrm{T}}$

\begin{tabular}{|c|c|c|c|c|}
\hline \multicolumn{4}{|c|}{ Peak $(m / z)$ of: } & \multirow[b]{2}{*}{ Fatty acids } \\
\hline$[\mathrm{M}-\mathrm{H}]^{-}$ & {$[\mathbf{M}+\mathbf{H}]^{+}$} & {$[\mathrm{M}+\mathrm{Na}]^{+}$} & $\begin{array}{l}{[\mathrm{M}+2} \\
\mathrm{Na}-\mathrm{H}]^{+}\end{array}$ & \\
\hline 662 & 664 & 686 & 708 & {$\left[C_{15.0} / C_{15.0}\right],\left[C_{14.0} / C_{16.0}\right]$} \\
\hline 676 & 678 & 700 & 722 & {$\left[\mathrm{C}_{15: 0} / \mathrm{C}_{16: 0}\right],\left[\mathrm{C}_{14: 0} / \mathrm{C}_{17: 0}\right]$} \\
\hline 690 & 692 & 714 & 736 & {$\left[\mathrm{C}_{16: 0} / \mathrm{C}_{16: 0}\right],\left[\mathrm{C}_{15: 0} / \mathrm{C}_{17: 0}\right]$} \\
\hline 704 & 702 & 728 & 750 & {$\left[\mathrm{C}_{17: 0} / \mathrm{C}_{16: 0}\right],\left[\mathrm{C}_{15: 0} / \mathrm{C}_{18: 0}\right]$} \\
\hline 718 & 720 & 742 & 764 & $\begin{array}{c}{\left[\mathrm{C}_{17: 0} / \mathrm{C}_{17: 0}\right],\left[\mathrm{C}_{16: 0} / \mathrm{C}_{18: 0}\right],} \\
{\left[\mathrm{C}_{15: 0} / \mathrm{C}_{19: 0}\right]}\end{array}$ \\
\hline
\end{tabular}

FAB-MS analysis of the highest ninhydrin-positive fractions and the lower one showed quasimolecular ions at $\mathrm{m} / \mathrm{z}$ $704,718,732$, and 746 for the highest one and at $m / z 662,676$, 690,704 , and 718 for the lower components. The negativeion FAB spectra showed intensive peaks at $m / z 194$ and 154 (characterizing PME) for the highest components and at $\mathrm{m} / \mathrm{z}$ 180 and 140 (characterizing PE) for the lower ones. The absence of the ions at $m / z 257,271,285$, and 313 atomic mass units (characterizing the hydroxylated fatty acids) suggests that both components are acylated with nonhydroxylated fatty acids (Tables 5 and 6 ).

The identities of the components which give rise to purpleness directly upon addition of the periodate-Schiff reagent and were tentatively identified as $P G$ were also supported by FAB-MS. FAB analysis of these components showed quasimolecular ions in the high-mass region at $\mathrm{m} / \mathrm{z}$ 707,721 , and 735 (Table 7). In the lower-mass region of the negative-ion FAB spectrum, intensive ions at $m / z 211,171$, 193, and 153 are characteristic of the phosphoglycerol portion of this phospholipid class. The above interpretation was also supported by tandem MS analysis of the daughter ion at $m / z 721$ (Fig. 7).

TLC revealed the presence of a very heavy spot in all of the strains which was tentatively identified as DPG. FAB-MS analysis of the partially purified components isolated from $A$. mediterranei ATCC $13685^{\mathrm{T}}$ showed some peaks in the higher-mass region $(m / z 1,000$ to 1,300$)$. However, because of the very low intensity of these peaks we were not able to interpret them; they may arise from quasimolecular ions and may correspond to a mixture of DPG with a different fatty acid composition. Peaks at $\mathrm{m} / \mathrm{z}$ 231,312 , and 319 were comparable to those obtained from a reference DPG. These ions were not found in the spectra of the other phospholipid classes, and therefore they may be regarded as characteristic for DPG.

\section{DISCUSSION}

The polar lipids of the genus Amycolatopsis are a complex mixture of many different lipid types. All of the strains contained mixtures of DPG, PG, and PI, which are acidic lipids, co-occurring with PE and PME, which are neutral lipids. The co-occurrence of acidic phospholipids with neutral ones is a phenomenon found in many bacteria $(17,23$, 32).

This characteristic polar lipid pattern readily distinguishes Amycolatopsis spp. from Nocardia spp. and other mycolic acid-containing taxa that contain DPG and characteristic PI mannosides (26), as well as from other mycolateless actinomycetes, such as Streptomyces spp. and related wall chemotype I actinomycetes which possess DPG, PE, PI, and PI mannosides $(16,20,23)$. This pattern also distinguishes
TABLE 7. Quasimolecular ion and fatty acid composition of PG isolated from $A$. azurea DSM $43854^{\mathrm{T}}$

\begin{tabular}{ccccc}
\hline \multicolumn{3}{c}{ Peak (m/z) of: } & \\
\cline { 1 - 3 }$[\mathrm{M}-\mathrm{H}]^{-}$ & {$[\mathrm{M}+\mathrm{H}]^{+}$} & {$[\mathrm{M}+\mathrm{Na}]^{+}$} & $\begin{array}{c}{[\mathrm{M}+2} \\
\mathrm{Na}-\mathrm{H}]^{+}\end{array}$ & \\
\hline 707 & 709 & 731 & 735 & {$\left[\mathrm{C}_{15: 0} / \mathrm{C}_{16: 0}\right],\left[\mathrm{C}_{14: 0} / \mathrm{C}_{17: 0}\right]$} \\
721 & 723 & 745 & 767 & {$\left[\mathrm{C}_{15: 0} / \mathrm{C}_{17: 0}\right],\left[\mathrm{C}_{16: 0} / \mathrm{C}_{16: 0}\right]$} \\
735 & 737 & 759 & 781 & {$\left[\mathrm{C}_{16: 0} / \mathrm{C}_{17: 0}\right],\left[\mathrm{C}_{15: 0} / \mathrm{C}_{18: 0}\right]$} \\
\hline
\end{tabular}

Amycolatopsis strains from Actinomadura strains which contain DPG, PI, and monoacylated PI mannosides as major phospholipids.

The presence of two forms of both PE and PME, one acylated with hydroxylated fatty acids and the other acylated with nonhydroxylated fatty acids, is to be regarded as a new chemotaxonomic characteristic for the differentiation of Amycolatopsis spp. from other actinomycetes. Hydroxy fatty acids, previously reported to be acylated to PE in certain streptomycetes $(14,16,30)$, were identified in some strains of the following genera: Actinoplanes, "streptomycetes of the chainia type," Microbispora, Nocardia, Pseudonocardia, "streptomycetes of the streptoverticillium type," and Streptosporangium. The phospholipids of such strains showed two spots containing PE on TLC plates: one acylated with nonhydroxylated fatty acids and a more polar compound acylated, at least in part, with hydroxy fatty acids (16). Collins et al. (6) reported the presence of DPG, PG, and two unidentified lipids in strains of Arthrobacter simplex and concluded that the latter might correspond to the hydroxy fatty acid-containing PG found by Yano et al. $(37,38)$. Pramanik et al. (31) reported the presence of a PE series with increasing chain lengths which are acylated with hydroxy fatty acids in the lipid isolated from Microbispora parva ATCC 33326, Saccharothrix mutabilis ATCC 31520, and Saccharothrix sp. strain SCC 1789. Yano et al. (36) reported that " $N$. leishmanmii" has PG and two PEs, one of which incorporates hydroxy fatty acids. The increasing number of reports on the detection of phospholipids acylated with hydroxylated fatty acids in members of the order Actinomycetales should be regarded as an important chemical marker that could be used to differentiate members of this order. In addition, this character will extend the number of the phospholipid types sensu Lechevalier.

MS is a very efficient tool for structural elucidation of

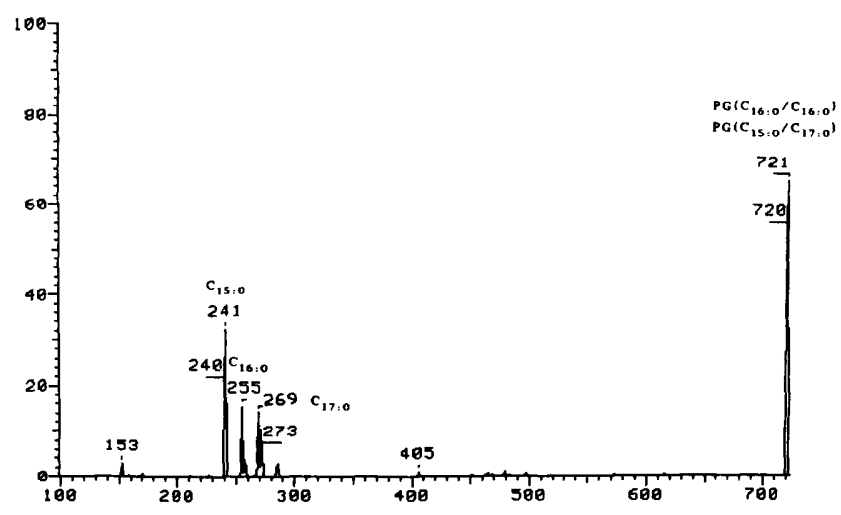
(PG). 
organic compounds. FAB-MS is not applied frequently in diagnostic laboratories. The positive- and negative-ion spectra of the bacterial extracts were found to reflect their distinctive phospholipid contents qualitatively $(11,12)$. Intensive peaks in the negative-ion FAB spectra at $\mathrm{m} / \mathrm{z} 299$, $259,281,241$, and 297 are characteristic for the inositol phosphate portion of PI, while those at $m / z 211,171,193$, and 153 are characteristic for the phosphoglycerol portion of PG. The ethanolamine phosphate portion of PE is characterized by intensive peaks at $\mathrm{m} / \mathrm{z} 180$ and 140, and the methylethanolamine phosphate portion of PME is characterized by peaks at $m / z 194$ and 154 .

It seems that the applicability, speed, and power of FAB-MS for identification of phospholipids and elucidation of their structures are much better than those of traditional methods, such as hydrolysis and chromatographic separation. This method may be used for differentiation of bacterial isolates at the genus level.

\section{REFERENCES}

1. Andrews, A. G. 1984. Estimation of amniotic fluid phospholipids by high-performance liquid chromatography. J. Chromatogr. 336:139-150.

2. Ayanoghi, E., A. Wegmann, O. Pilet, G. D. Marburg, J. R. Hass, and C. Djerassi. 1984. Mass spectrometry of phospholipids. Some applications of desorption chemical ionization and fast atom bombardment. J. Am. Chem. Soc. 106:5246-5251.

3. Baddiley, J., J. G. Buchanan, R. E. Handschumacher, and J. F. Prescott. 1956. Chemical studies in the biosynthesis of purine nucleotides. Part I. The preparation of N-glycylglycosylamines. J. Chem. Soc. 3:2818-2823.

4. Barber, M., R. S. Bordoli, R. D. Sedgwick, and A. N. Tyler. 1981. Fast atom bombardment of solids (F.A.B.): a new ion source for mass spectrometry. J. Chem. Soc. Chem. Commun. 1981:325-327.

5. Beiss, U. 1984. Zur papierchromatographischen Auftrennung von Pflanzenlipiden. J. Chromatogr. 13:104-110.

6. Collins, M. D., M. Goodfellow, and D. E. Minnikin. 1982. Polar lipid composition in the classification of Arthrobacter and Microbacterium. FEMS Microbiol. Lett. 15:299-302.

7. Dittmer, J. C. F., and R. L. Lester. 1964. A simple, specific spray for the detection of phospholipids on thin-layer chromatograms. J. Lipid Res. 5:126-127.

8. Fenwick, G. R., J. Eagles, and R. Self. 1983. Fast atom bombardment mass spectrometry of intact phospholipids and related compounds. Biomed. Mass Spectrom. 10:382-386.

9. Games, D. E. 1978. Soft ionization mass spectral methods for lipid analysis. Chem. Phys. Lipids 21:389-402.

10. Goodfellow, M., and D. E. Minnikin. 1981. Classification of nocardioform bacteria. Zentralbl. Bakteriol. Mikrobiol. Hyg. I Abt. Suppl. 11:7-16.

11. Heller, D. N., R. J. Cotter, C. Fenselau, and O. M. Uy. 1987. Profiling of bacteria by fast atom bombardment mass spectrometry. Anal. Chem. 59:2806-2809.

12. Heller, D. N., C. M. Murphy, R. J. Cotter, C. Fenselau, and O. M. Uy. 1988. Constant neutral scanning for the characterization of bacterial phospholipids desorbed by fast atom bombardment mass spectrometry. Anal. Chem. 60:2787-2791.

13. Jacin, H., and A. R. Mishkin. 1965. Separation of carbohydrate on borate-impregnated silica gel G plates. J. Chromatogr. 18: $170-173$.

14. Kawanami, J. 1971. Lipids of Streptomyces sioyaensis on the structure of siolipin. Chem. Phys. Lipids 7:158-172.

15. Komura, I., K. Yamada, S. Otsuka, and K. Komagata. 1975. Taxonomic significance of phospholipids in coryneform and nocardioform bacteria. J. Gen. Appl. Microbiol. 21:251-261.

16. Lechevalier, M. P., C. de Biévre, and H. A. Lechevalier. 1977. Chemotaxonomy of aerobic actinomycetes: phospholipid composition. Biochem. Syst. Ecol. 5:249-260.

17. Lechevalier, M. P., H. Prauser, D. P. Labeda, and J.-S. Ruan.
1986. Two new genera of nocardioform actinomycetes: Amycolata gen. nov. and Amycolatopsis gen. nov. Int. J. Syst. Bacteriol. 36:29-37.

18. Lechevalier, M. P., A. E. Stern, and H. A. Lechevalier. 1981. Phospholipids in the taxonomy of actinomycetes. Zentralbl. Bakteriol. Mikrobiol. Hyg. I Abt. Suppl. 11:111-116.

19. Lehmann, W. D., and M. Kessler. 1983. Fatty acid profiling of phospholipids by field desorption and fast atom bombardment mass spectrometry. Chem. Phys. Lipids 32:123-135.

20. Minnikin, D. E., and M. Goodfellow. 1976. Lipid composition in the classification and identification of nocardiae and related taxa, p. 160-219. In M. Goodfellow, G. H. Brownell, and J. A. Serrano (ed.), The biology of nocardiae. Academic Press, London.

21. Minnikin, D. E., and M. Goodfellow. 1978. Polar lipids of nocardioform and related bacteria. Zentralbl. Bakteriol. Parasitenkd. Infekt. Hyg. I Abt. Suppl. 6:75-83.

22. Minnikin, D. E., and M. Goodfellow. 1980. Lipid composition in the classification of acid-fast bacteria, p. 189-256. In M. Goodfellow and R. G. Board (ed.), Microbiological classification and identification. Academic Press, London.

23. Minnikin, D. E., and M. Goodfellow. 1981. Lipids in the classification of actinomycetes. Zentralbl. Bakteriol. Mikrobiol. Hyg. I Abt. Suppl. 11:99-109.

24. Minnikin, D. E., M. Goodfellow, and M. D. Collins. 1978. Lipid composition in the classification and identification of coryneform and related taxa, p. 85-160. In I. J. Bousfield and A. G. Callely (ed.), Coryneform bacteria. Academic Press, London.

25. Minnikin, D. E., A. G. O'Donnell, M. Goodfellow, G. Alderson, M. Athayle, K. P. Schaal, and J. H. Parlett. 1984. An integrated procedure for the extraction of bacterial isoprenoid quinones and polar lipids. J. Microbiol. Methods 2:233-241.

26. Minnikin, D. E., P. V. Patel, L. Alshamaony, and M. Goodfellow. 1977. Polar lipid composition in the classification of Nocardia and related bacteria. Int. J. Syst. Bacteriol. 27:104-117.

27. Minnikin, D. E., T. Pirouz, and M. Goodfellow. 1977. Polar lipid composition in the classification of some Actinomadura species. Int. J. Syst. Bacteriol. 27:118-121.

28. Münster, H., and H. Budzikiewicz. 1988. Structural and mixture analysis of glycerolphosphoric acid derivatives by fast atom bombardment tandem mass spectrometry. Biol. Chem. HoppeSeyler 369:303-308.

29. Münster, H., J. Stein, and H. Budzikiewicz. 1986. Structure analysis of underivatized phospholipids by negative ion fast atom bombardment mass spectrometry. Biomed. Environ. Mass Spectrom. 13:423-427.

30. Pommier, M. T., and G. Michel. 1973. Phospholipid and acid composition of Nocardia and nocardioid bacteria as criteria of classification. Biochem. Syst. 1:3-12.

31. Pramanik, B. N., J. M. Zechman, P. R. Das, and P. L. Bartner. 1990. Bacterial phospholipid analysis by fast atom bombardment mass spectrometry. Biomed. Environ. Mass Spectrom. 19:164-170.

32. Shaw, N. 1974. Lipid composition as a guide to the classification of bacteria. Adv. Appl. Microbiol. 17:63-108.

33. Vaskovsky, V. E., and E. Y. Kostetsky. 1968. Modified spray for the detection of phospholipids on thin-layer chromatograms. J. Lipid Res. 9:396.

34. Wagner, H., L. Hörhammer, and P. Wolff. 1961. Dünnschichtchromatographie von Phosphatiden und Glykolipiden. Biochem. Z. 334:175.

35. Wood, G. W., and P. Y. Lau. 1974. Analysis of intact phospholipids by field desorption mass spectrometry. Biomed. Mass Spectrom. 1:154-155.

36. Yano, I., Y. Furukawa, and M. Kusunove. 1970. $\alpha$-Hydroxy fatty acid-containing phospholipids of Nocardia leishmanii. Biochim. Biophys. Acta 202:189-191.

37. Yano, I., Y. Furukawa, and M. Kusunove. 1971. Fatty acid composition of Arthrobacter simplex grown on hydrocarbons. Occurrence of $\alpha$-hydroxy acid. Eur. J. Biochem. 23:220-228.

38. Yano, I., Y. Furukawa, and M. Kusunove. 1971. Conversion of $\alpha$-hydroxy fatty acid to pentadecanoic acid by resting cells of Arthrobacter simplex. J. Gen. Appl. Microbiol. 17:429-432. 